\title{
Early programmes of high and low intensity exercise and quality of life after acute myocardial infarction
}

\author{
Marian C Worcester, David L Hare, R Graeme Oliver, Michael A Reid, Alan J Goble
}

\begin{abstract}
Objective-To determine whether a group programme of light exercise could improve quality of life in patients after acute myocardial infarction to the same extent as a high intensity exercise training programme.
\end{abstract}

Setting-Australian teaching hospital.

Patients-224 men from a consecutive series of 339 men under 70 admitted to a coronary care unit with transmural acute myocardial infarction.

Intervention-Patients were randomly allocated in hospital to a group programme lasting eight weeks of either high intensity exercise training or light exercise.

Main outcome measures-Physical working capacity based on metabolic equivalents achieved from treadmill exercise tests at entry, after 11 weeks, and after one year. Quality of life based on self report scores of anxiety, depression, denial, and wellbeing and interview assessments of activities and psychosocial adjustment at entry, after four months, and after one year.

Results-The two groups were well matched at entry. At 11 weeks the mean results of treadmill testing were $10.7(95 \%$ confidence interval 10.20 to 11.20) metabolic equivalents for exercise training and $9.7(9.26$ to $10 \cdot 14)$ for light exercise $(t=2.85$, $\mathrm{df}=181, \mathrm{p}=0.005)$. Apart from this small temporary benefit in mean physical working capacity, there were no significant differences between groups. Improvement in occupational adjustment score from baseline to four months was greater after exercise training than after light exercise, but at one year repeated measures analysis of variance showed no significant effects of treatment or interaction between treatment and time point.

Conclusion-The effects on quality of life of a low cost programme of light exercise are similar to those obtained from a high intensity exercise training programme.

\section{Introduction}

Psychological and social problems after acute myocardial infarction are often considerable and may persist for months or years. ${ }^{1-3}$ Exercise training programmes have been recommended to facilitate recovery from myocardial infarction. ${ }^{4-6}$ Such programmes are usually based on walking and jogging, starting in the third week after myocardial infarction and lasting for six to eight weeks. ${ }^{6}$

High intensity exercise training improves performance on a treadmills ${ }^{7}$ and psychological functioning. ${ }^{8-9}$ These benefits, however, may result not from the exercise training itself but from supervised group activity. Thus a light exercise programme could provide the same physical, social, and psychological benefits.

Light exercise is the basis of most of the group exercise programmes offered in Australian outpatient departments. Such programmes aim at giving patients confidence to undertake a walking programme at home and to resume normal daily activities, facilitating spontaneous recovery of physical performance after myocardial infarction. Aerobic exercise training programmes are expensive, requiring repeated exercise testing, medical supervision, and, in view of the risk of cardiac arrest, ${ }^{\circ}$ facilities for cardiopulmonary resuscitation. Light exercise programmes, however, are cheap and the risks of training do not need to be comprehensively assessed for each patient. They are usually conducted by a nurse or physiotherapist in a hospital room and are therefore convenient for patients to attend during convalescence.

The Austin Hospital cardiac rehabilitation trial was set up to determine whether the benefits of group exercise training could be equally well achieved by a less costly group programme of light exercise. We previously reported that exercise training compared with light exercise produced only a small temporary benefit in physical working capacity. ${ }^{10} \mathrm{We}$ now report a comprehensive evaluation of the possible benefits of exercise training compared with light exercise on the quality of life.

\section{Methods}

Men under 70 years who had been admitted consecutively to a single coronary care unit with transmural ( $Q$ wave) acute myocardial infarction were eligible for the study. Transmural myocardial infarction was determined according to electrocardiographic criteria of the World Health Organisation-namely, new abnormal $Q$ waves and the development of characteristic ST and T wave changes. ${ }^{11}$

Short and long term prognostic indices were calculated for all patients. ${ }^{1213}$ The site of infarction was determined from an electrocardiogram. ${ }^{14}$ Clinical heart failure was graded by Killip class. ${ }^{15}$ Gradings of radiological heart size were assessed from a portable chest radiograph. ${ }^{12} \mathrm{~A}$ history of ischaemia and infarction was noted, as was electrical reversion from ventricular fibrillation. Patients were excluded from the study for defined medical and other reasons. ${ }^{10}$

At discharge from the coronary care unit patients were randomly allocated to a rehabilitation programme of exercise training or light exercise. ${ }^{16}$ All patients were treated by the same staff and given the same advice and printed information, and they had the same baseline evaluations. All patients gave their informed consent to participation in the study.

\section{EXERCISE PROGRAMMES}

The exercise training programme complied with the recommendations of the American Heart Association. ${ }^{6}$ It consisted of three one hour classes a week conducted by a teacher of physical education in a gymnasium owned by the YMCA (Young Men's Christian Association) and attended by a doctor. ${ }^{10}$ Light exercise consisted of two one hour classes a week of light calisthenics and intermittent exercises with rests between. Classes were conducted by a physiotherapist in the outpatient physiotherapy room. ${ }^{10}$ Most patients first attended their programme in the second week (8-14 days) after infarction to watch the class and started exercising in the third week (15-21 days). 
Patients in both groups were also asked to walk each day at a comfortable pace for at least 30 minutes.

Maximal, symptom limited treadmill tests were performed in the third and 11 th week after myocardial infarction and at 12 months. Test results were converted to metabolic equivalents (or multiples of resting metabolic expenditure) determined from standard nomograms. ${ }^{178}$

\section{ASSESSMENT OF QUALITY OF LIFE}

Quality of life is complex and many faceted. Several psychological and social indices were used rather than a composite index of quality of life so that each variable could be measured separately. The Spielberger state trait anxiety inventory ${ }^{19}$ and IPAT (Institute for Personality and Ability Testing) depression scale ${ }^{20}$ have been used in various clinical populations and research settings $^{919-21}$ and are considered to be suitable for measuring affective responses of patients with a medical illness. Spielberger's trait anxiety scale measures the stable condition of anxiety proneness, while state or current anxiety reflects the degree of anxiety, which may fluctuate after illness. ${ }^{19}$ The Hackett-Cassem denial scale was developed to investigate the degree of psychological denial in patients with heart disease..$^{22}$ The Eysenck personality inventory is commonly used for measuring neuroticism and extroversion. ${ }^{23}$ Sense of wellbeing was determined from patients' ratings on a visual analogue scale, with responses ranging from "never felt worse" to "never felt better" being scored on a scale from 0 to $10 .{ }^{24}$

TABLE I-Baseline clinical characteristics of patients randomly allocated to exercise training or light exercise after myocardial infarction. Values are numbers (percentages) of patients with $95 \%$ confidence intervals unless stated otherwise

\begin{tabular}{|c|c|c|}
\hline & $\begin{array}{l}\text { Exercise training } \\
\quad(n=108)\end{array}$ & $\begin{array}{l}\text { Light exercise } \\
\qquad(\mathrm{n}=116)\end{array}$ \\
\hline Mean (SE) age (years) & $54.8(0.8) 53.2$ to 56.2 & $53.9(0.8) 52.3$ to 55.3 \\
\hline \multicolumn{3}{|l|}{ Mean (SE) peak enzyme activity (IU): } \\
\hline Creatine kinase & $1942(110) 1722$ to 2162 & 2179 (127) 1925 to 2433 \\
\hline Aspartate aminotransaminase & 303 (17) 269 to 337 & 327 (18) 291 to 363 \\
\hline \multicolumn{3}{|l|}{ Mean (SE) coronary prognostic indices: } \\
\hline Norris short term & $5.8(0.2) 5.4$ to 6.2 & $5.6(0.2) 5.2$ to 6.0 \\
\hline Norris long term & $3.9(0.3) 3.3$ to 4.5 & $3.9(0.3) 3.3$ to 4.5 \\
\hline \multicolumn{3}{|l|}{ Infarct site: } \\
\hline Anterior or lateral & 53 (49) 39.6 to 58.5 & 41 (35) $26 \cdot 6$ to $44 \cdot 0$ \\
\hline Inferior or posterior & 55 (51) 41.5 to 60.4 & $75(65) 56.0$ to 73.4 \\
\hline \multicolumn{3}{|l|}{ Clinical heart failure: } \\
\hline Lungs clear & $58(54) 44.3$ to $63 \cdot 1$ & $71(61) 52 \cdot 3$ to $70 \cdot 1$ \\
\hline Basal crepitations & $42(39) 29 \cdot 7$ to $48 \cdot 1$ & 37 (32) 23.4 to $40 \cdot 4$ \\
\hline Upper crepitations & 8 (7) 2.5 to 12.3 & 8 (7) 2.3 to 11.5 \\
\hline \multicolumn{3}{|l|}{ Radiological heart size } \\
\hline Normal & $67(63) 57.9$ to 71.2 & 77 (66) 57.8 to $75 \cdot 0$ \\
\hline Borderline & $30(28) 19 \cdot 3$ to $36 \cdot 2$ & $28(24) 16.4$ to 31.9 \\
\hline Enlarged & $9(9) 3.1$ to 13.5 & $11(10) 4 \cdot 2$ to $14 \cdot 8$ \\
\hline Previous infarction & $11(10) 4.5$ to 15.9 & $12(10) 4.8$ to 15.9 \\
\hline Previous ischaemia & $30(28) 19 \cdot 3$ to $36 \cdot 2$ & 30 (26) 17.9 to 33.8 \\
\hline Electrical reversion & $11(10) 4.5$ to 15.9 & $7(6) 1.7$ to 10.4 \\
\hline
\end{tabular}

${ }^{\star}$ Normal values $<180$ IU. †Normal values $<30$ IU.

TABLE II-Baseline sociodemographic characteristics of patients randomly allocated to exercise training or light exercise after myocardial infarction

\begin{tabular}{|c|c|c|c|c|}
\hline & \multicolumn{2}{|c|}{$\begin{array}{l}\text { Exercise training } \\
\quad(n=108)\end{array}$} & \multicolumn{2}{|c|}{$\begin{array}{l}\text { Light exercise } \\
\quad(n=116)\end{array}$} \\
\hline & $\begin{array}{l}\text { No }(\%) \text { of } \\
\text { patients }\end{array}$ & $\begin{array}{l}95 \% \text { Confidence } \\
\text { interval }\end{array}$ & $\begin{array}{l}\text { No (\%) of } \\
\text { patients }\end{array}$ & $\begin{array}{l}95 \% \text { Confidence } \\
\text { interval }\end{array}$ \\
\hline \multicolumn{5}{|c|}{ Education (No of years): } \\
\hline$<9$ & $36(33)$ & $24 \cdot 4$ to $42 \cdot 2$ & $37(32)$ & 23.4 to 40.4 \\
\hline $9-10$ & $43(40)$ & 30.6 to 49.0 & $53(46)$ & 36.6 to 54.8 \\
\hline$>10$ & $29(27)$ & $18 \cdot 5$ to $35 \cdot 2$ & $26(22)$ & 14.8 to 30.0 \\
\hline \multicolumn{5}{|l|}{ Occupational class: } \\
\hline White collar & $54(50)$ & 40.6 to 59.4 & $47(41)$ & 31.6 to 49.5 \\
\hline Blue collar & $54(50)$ & 40.6 to 59.4 & $69(59)$ & 50.5 to 68.4 \\
\hline \multicolumn{5}{|l|}{ Employment status: } \\
\hline In workforce: & $81(75)$ & $66 \cdot 8$ to $83 \cdot 2$ & $88(76)$ & 68.1 to 83.6 \\
\hline Employed & $81(75)$ & $66 \cdot 8$ to $83 \cdot 2$ & $84(72)$ & 64.3 to 80.5 \\
\hline Unemployed & 0 & & $4(3)$ & 0.1 to 6.8 \\
\hline \multirow{2}{*}{\multicolumn{5}{|c|}{$\begin{array}{l}\text { Ketured } \\
\text { Smoking status: }\end{array}$}} \\
\hline & & & & \\
\hline Smoker & $60(56)$ & $46 \cdot 2$ to $64 \cdot 9$ & $62(53)$ & 44.4 to 62.5 \\
\hline Non-smoker & $48(44)$ & $35 \cdot 1$ to $53 \cdot 8$ & $54(47)$ & 37.5 to 55.6 \\
\hline \multicolumn{5}{|l|}{ Sexual activity: } \\
\hline Active & $92(85)$ & 78.5 to 91.9 & $97(84)$ & 76.9 to 90.4 \\
\hline Non-active & $16(15)$ & 8.1 to 21.5 & $19(16)$ & $9 \cdot 6$ to $23 \cdot 1$ \\
\hline
\end{tabular}

Baseline measures of denial, extroversion, neuroticism, anxiety, depression, and wellbeing were obtained in hospital and before entry to the programmes. Anxiety, depression, and sense of wellbeing were also assessed after four and 12 months. Inventories and scales were completed before the interviews and scored by an independent rater.

The semistructured interview to investigate social functioning was adapted from the structured and scaled interview to assess maladjustment ${ }^{25}$-which has been used in previous investigations of outcome after myocardial infarction, ${ }^{8}$ - and the social adjustment scale developed from it. ${ }^{26}$ The schedule was tested during a pilot study and appropriately modified. Structured questions were followed by suitable probing questions; responses referred to the previous two months.

Total scores for each scale ranged from 0 to 24 for social adjustment, 0 to 20 for marital adjustment, and 0 to 16 for occupational adjustment. Higher scores reflected better adjustment. Sexual recovery was assessed according to whether patients perceived their usual sexual activities to be as satisfying as or more satisfying than before they were admitted to hospital. Whether patients smoked and the effect of their myocardial infarction on employment were included among the psychosocial end points of the study. Occupational class was defined for current or last occupation as white or blue collar. Men in professional, managerial, or clerical jobs were defined as white collar workers, while those with skilled, semiskilled, or unskilled manual jobs were defined as blue collar workers. ${ }^{27}$ Interviews were tape recorded and scores independently checked.

\section{ANALYSIS}

Analysis was undertaken on an intention to treat basis. All patients were followed up for 12 months. Baseline and end point (at four and 12 months) measures for the two groups were compared, as were changes in patients' scores between assessments. For categorical variables $\chi^{2}$ or Fisher's exact tests were used when appropriate. For numerical data $t$ tests were used. As some data were skewed, non-parametric Mann-Whitney and Kolmogarov-Smirnov two sample tests were also performed. For patients who underwent assessment on psychosocial measures at all three assessment times repeated measures analysis of variance were performed to assess the interaction between treatment group and time point, as well as the effect of treatment. All tests were performed to assess the interaction between treatment group and time point, as well as the effect of treatment. All tests were performed using SPSS-X. ${ }^{28}$ Differences between groups not achieving significance at a 0.05 level (two sided) are described as not significant.

The psychosocial assessments constitute part of the last three years of our five year study..$^{10}$ The numbers of patients recruited to this part of the study were calculated to be sufficient to detect, for numerical measures, a difference between group means of $0.5 \mathrm{SD}$ at $5 \%$ significance with $95 \%$ power, and, for dichotomous measures, a difference of $20 \%$ in the proportion showing the attribute, with similar levels of significance and power.

\section{Results}

During the three years of enrolment 339 men satisfied the criteria for entry to the study. One hundred and fifteen were excluded because of death (29), cardiogenic shock (four), physical disability (24), distance from the programme venues (24), inadequate command of English (12), anticipated non-compliance with the programme (11), psychological disability 


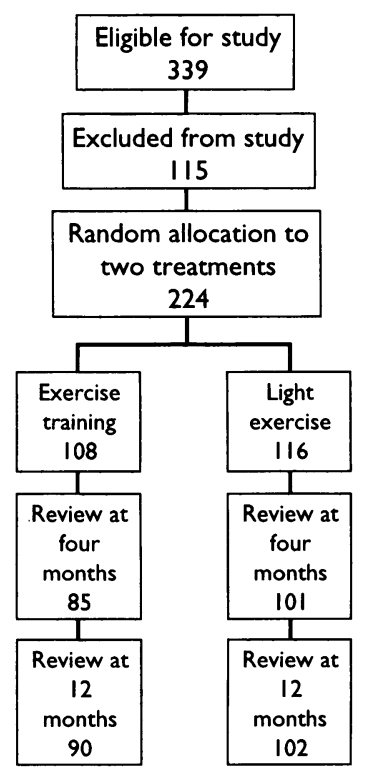

Eligibility, random allocation, and follow up of patients in study

\begin{tabular}{|c|c|c|c|c|c|c|}
\hline & \multicolumn{3}{|c|}{ Exercise training } & \multicolumn{3}{|c|}{ Light exercise } \\
\hline & $\begin{array}{c}\text { No of } \\
\text { patients }\end{array}$ & Mean (SE) & $\begin{array}{l}95 \% \text { Confidence } \\
\text { interval }\end{array}$ & $\begin{array}{c}\text { No of } \\
\text { patients }\end{array}$ & Mean (SE) & $\begin{array}{l}\text { 95\% Confidence } \\
\text { interval }\end{array}$ \\
\hline Denial (Hackett-Cassem scale) & 108 & $11.43(0.53)$ & 10.39 to 12.46 & 116 & $12.85(0.53)$ & 11.81 to 13.88 \\
\hline Extroversion (Eysenck personality inventory) & 101 & $10.33(0.40)$ & 9.55 to 11.00 & 104 & $10.56(6.38)$ & 9.83 to 11.33 \\
\hline Neuroticism (Eysenck personality inventory) & 101 & $9.54(0.53)$ & 8.50 to 10.57 & 104 & $9.60(0.51)$ & 8.59 to 10.60 \\
\hline Trait anxiety (Spielberger state trait anxiety inventory) & 99 & $34.89(0.78)$ & 33.37 to 36.41 & 100 & $35.69(0.83)$ & 34.07 to 37.81 \\
\hline
\end{tabular}

(three), contamination, based on expressed preference for one or other programme (five), and early transfer to another hospital or administrative error (three). The figure shows the distribution of patients who were excluded from the study, who were randomly allocated to an exercise programme, and who attended the follow up examinations.

Patients in each group were well matched on all physical, sociodemographic, and personality characteristics (tables I-III); there were no significant differ-

TABLE IV-Reasons for non-attendance at four and 12 month reviews in both groups of patients

\begin{tabular}{lcccccc}
\hline & \multicolumn{2}{c}{ At 4 months } & & \multicolumn{2}{c}{ At 12 months } \\
\cline { 2 - 3 } \cline { 5 - 6 } & $\begin{array}{c}\text { Exercise } \\
\text { training } \\
(\mathrm{n}=22)\end{array}$ & $\begin{array}{c}\text { Light } \\
\text { exercise } \\
(\mathrm{n}=15)\end{array}$ & & $\begin{array}{c}\text { Exercise } \\
\text { training } \\
(\mathrm{n}=18)\end{array}$ & $\begin{array}{c}\text { Light } \\
\text { exercise } \\
(\mathrm{n}=14)\end{array}$ \\
\hline $\begin{array}{l}\text { Death } \\
\text { Bypass surgery }\end{array}$ & 9 & 7 & & 10 & 9 \\
Physical disability & 3 & $\overline{2}$ & & 1 & - \\
Non-compliance & 6 & 6 & & 5 & 1 \\
\hline
\end{tabular}

${ }^{\star}$ Cumulative scores: three patients died between reviews, one in exercise training group and two in light exercise group.

TABLE V-Psychosocial scores in patients four and 12 months after random allocation to exercise training or light exercise

\begin{tabular}{|c|c|c|c|c|c|c|}
\hline & \multicolumn{3}{|c|}{$\begin{array}{l}\text { Exercise training } \\
\quad(\mathrm{n}=108)\end{array}$} & \multicolumn{3}{|c|}{$\begin{array}{l}\text { Light exercise } \\
(\mathrm{n}=116)\end{array}$} \\
\hline & $\begin{array}{c}\text { No of } \\
\text { patients }\end{array}$ & Mean (SE) & $\begin{array}{l}95 \% \text { Confidence } \\
\text { interval }\end{array}$ & $\begin{array}{c}\text { No of } \\
\text { patients }\end{array}$ & Mean (SE) & $\begin{array}{l}95 \% \text { Confidence } \\
\text { interval }\end{array}$ \\
\hline \multicolumn{7}{|l|}{ Anxiety state: } \\
\hline On admission & 100 & $33.65(0.94)$ & 31.81 to 35.49 & 100 & $33 \cdot 27(1.05)$ & $31 \cdot 21$ to $35 \cdot 33$ \\
\hline At 4 months & 83 & $30 \cdot 95(1 \cdot 16)$ & 28.68 to 33.22 & 92 & $31.78(1.17)$ & $29 \cdot 50$ to $34 \cdot 07$ \\
\hline At 12 months & 83 & $31.59(1.02)$ & 29.60 to 33.58 & 90 & $32 \cdot 24(1.04)$ & $30 \cdot 20$ to $34 \cdot 29$ \\
\hline \multicolumn{7}{|l|}{ Depression: } \\
\hline On admission & 90 & $10.99(0.89)$ & $9 \cdot 25$ to 12.73 & 98 & $12.76(1.02)$ & $10 \cdot 76$ to 14.75 \\
\hline At 4 months & 84 & $11.32(1.04)$ & 9.29 to 13.35 & 92 & $11.74(1.06)$ & 9.67 to 13.81 \\
\hline At 12 months & 83 & $11.48(1.03)$ & 9.47 to 13.49 & 90 & $13.06(1.23)$ & 10.65 to 15.46 \\
\hline \multicolumn{7}{|l|}{ Wellbeing: } \\
\hline On admission & 106 & $7 \cdot 91(0 \cdot 18)$ & 7.55 to 8.26 & 113 & $8.01(0.19)$ & 7.64 to 8.37 \\
\hline At 4 months & 85 & $8.33(0.16)$ & 8.03 to 8.63 & 100 & $8.08(0 \cdot 18)$ & 7.72 to 8.43 \\
\hline At 12 months & 87 & $7.91(0.19)$ & 7.54 to 8.27 & 100 & $7 \cdot 77(0 \cdot 19)$ & $7 \cdot 39$ to 8.12 \\
\hline \multicolumn{7}{|l|}{ Social adjustment: } \\
\hline On admission & 108 & $17.56(0.34)$ & 16.90 to 18.21 & 116 & $16.87(0.38)$ & $16 \cdot 17$ to $17 \cdot 87$ \\
\hline At 4 months & 85 & $16.87(0.42)$ & 16.05 to $17 \cdot 70$ & 101 & $16.68(0.37)$ & $15 \cdot 96$ to $17 \cdot 40$ \\
\hline At 12 months & 90 & $17.00(0.35)$ & 16.31 to $17 \cdot 69$ & 102 & $16.69(0.39)$ & 15.92 to 17.45 \\
\hline \multicolumn{7}{|c|}{ Marital adjustment: } \\
\hline On admission & 98 & $16.07(0.28)$ & $15 \cdot 52$ to $16 \cdot 62$ & 106 & $15 \cdot 63(0 \cdot 26)$ & $15 \cdot 12$ to $16 \cdot 15$ \\
\hline At 4 months & 76 & $15.34(0.34)$ & 14.69 to 16.00 & 93 & $15 \cdot 68(0 \cdot 29)$ & $15 \cdot 11$ to $16 \cdot 24$ \\
\hline At 12 months & 81 & $14.89(0.35)$ & $14 \cdot 20$ to $15 \cdot 58$ & 93 & $15 \cdot 13(0 \cdot 28)$ & 14.58 to 15.68 \\
\hline \multicolumn{7}{|c|}{ Occupational adjustment: } \\
\hline On admission & 79 & $11.79(0.26)$ & $11 \cdot 29$ to $12 \cdot 28$ & 84 & $11.44(0.31)$ & 10.83 to 12.05 \\
\hline At 4 months & 60 & $12.33(0.28)$ & 11.79 to 12.88 & 66 & $11.42(0.37)$ & $10 \cdot 70$ to $12 \cdot 15$ \\
\hline At 12 months & 59 & $12.29(0 \cdot 28)$ & 11.75 to 12.83 & 60 & $11.65(0.35)$ & 10.97 to 12.33 \\
\hline
\end{tabular}

TABLE VI-Behavioural characteristics of patients four and 12 months after random allocation to exercise training or light exercise

\begin{tabular}{|c|c|c|c|c|c|c|}
\hline & \multicolumn{3}{|c|}{ Exercise training } & \multicolumn{3}{|c|}{ Light exercise } \\
\hline & $\begin{array}{l}\text { Total } \\
\text { No of } \\
\text { patients }\end{array}$ & $\begin{array}{c}\text { No (\%) } \\
\text { of patients }\end{array}$ & $\begin{array}{l}95 \% \text { Confidence } \\
\text { interval }\end{array}$ & $\begin{array}{c}\text { Total } \\
\text { No of } \\
\text { patients }\end{array}$ & $\begin{array}{c}\text { No (\%) } \\
\text { of patients }\end{array}$ & $\begin{array}{l}95 \% \text { Confidence } \\
\text { interval }\end{array}$ \\
\hline \multicolumn{7}{|l|}{ Working status: } \\
\hline Working on admission & 81 & $81(100)$ & & 88 & $84(95)$ & \\
\hline Working at 4 months & 75 & $67(89)$ & $82 \cdot 3$ to $96 \cdot 3$ & 83 & $71(86)$ & 78.0 to 93.1 \\
\hline Working at 12 months & 75 & $64(85)$ & $77 \cdot 3$ to $93 \cdot 3$ & 83 & $66(80)$ & $70 \cdot 8$ to 88.2 \\
\hline \multicolumn{7}{|l|}{ Sexual status: } \\
\hline Active on admission & 92 & $92(100)$ & & 97 & $97(100)$ & \\
\hline Recovered at 4 months & 64 & $51(80)$ & 69.8 to 89.5 & 86 & $66(77)$ & $67 \cdot 8$ to $85 \cdot 2$ \\
\hline Recovered at 12 months & 69 & $55(80)$ & $70 \cdot 2$ to $89 \cdot 2$ & 89 & $71(80)$ & 71.4 to 88.1 \\
\hline \multicolumn{7}{|l|}{ Smoking status: } \\
\hline On admission & 60 & $60(100)$ & & 62 & $62(100)$ & \\
\hline At 4 months & 45 & $4(9)$ & 0.6 to 17.2 & 55 & $10(18)$ & 8.0 to 28.4 \\
\hline At 12 months & 50 & $14(28)$ & $15 \cdot 6$ to $40 \cdot 4$ & 51 & $19(37)$ & 24.0 to 50.5 \\
\hline
\end{tabular}

ences between groups. Eight patients in each group had pulmonary oedema. Furthermore, there were no significant differences between the two groups in the use of cardioactive or other drugs at baseline, at four months, or at 12 months. ${ }^{10}$

Table IV shows the reasons for non-attendance. The most common reason was death. Ten patients died in the exercise training group and nine in the light exercise group. Of these 19 patients, nine died before their entry exercise test, seven before completing the programme, and three before the 12 month review. A few patients in each group declined to be interviewed or to undergo exercise testing.

As previously reported, ${ }^{10}$ results from treadmill tests showed no differences between the groups except immediately on completion of the programmes. At entry patients were well matched in terms of their mean results on treadmill testing $(6.7(95 \%$ confidence interval $6 \cdot 22$ to $7 \cdot 18$ ) metabolic equivalents in exercise training group $v 6 \cdot 6(6 \cdot 10$ to $7 \cdot 10)$ metabolic equivalents in light exercise group). After eight weeks the results were $10 \cdot 7(10 \cdot 20$ to $11 \cdot 20)$ metabolic equivalents for exercise training and $9.7(9.26$ to $10 \cdot 14)$ metabolic equivalents for light exercise $(t=2 \cdot 85$, $\mathrm{df}=181, \mathrm{p}=0.005)$. At the 12 month review there was no significant difference between groups (10.6 (10.14 to 11.06 ) metabolic equivalents in exercise training group $v 10.5(10.06$ to 10.94$)$ metabolic equivalents in light exercise group).

No significant differences were found between groups in any of the measures of psychological functioning or quality of life at the four and 12 month reviews (tables $\mathrm{V}$ and VI). Analyses of skewed numerical data using Mann-Whitney and Kolmogarov-Smirnov two sample tests also showed no significant differences. Furthermore, there was no overall difference between groups in the rate of return to work of survivors who were previously in the workforce. The four men in the light exercise group who were unemployed at entry remained unemployed throughout the year. Although the mean improvement in the score for occupational adjustment was significantly greater in the exercise training group $(0.70(0.16$ to 1.23$) v-0.29(-0.93$ to 0.36$) ; t=2 \cdot 27, \mathrm{df}=123$, $\mathrm{p}=0.025$ ), there was no significant difference between the two groups in the change from baseline to 12 months. Repeated measures analysis of variance showed no significant effects of treatment or interactions between treatment and time point, although for occupational adjustment the interaction effect approached significance $(p=0.054)$.

Some patients were unable to complete self report inventories or respond adequately to interview questions. Therefore, there are varying numbers of patients whose personality characteristics are recorded in table III and whose psychosocial scores are recorded in table V. Working, sexual, and smoking outcomes (table VI) refer only to those patients who at the time of hospital admission were respectively in the workforce, sexually active, or smokers.

\section{Discussion}

The physical and psychological benefits of exercise training have been extensively investigated, but they 
are not directly attributable to the intensity of the exercise itself. In a smaller study by Blumenthal et al no difference was found between high and low intensity exercise training in either physical working capacity ${ }^{29}$ or psychosocial functioning. ${ }^{30} \mathrm{We}$ found that, although exercise training confers a greater physical benefit in the short term, ${ }^{10}$ a programme of light exercise can produce essentially the same level of psychosocial functioning as that achieved through exercise training. The effects of group exercise programmes on the quality of life, as reflected by psychological or social adjustment scores, seem to be independent of exercise intensity and whether groups are held two or three times a week.

The improvement in occupational adjustment in the exercise training group at four months (but not at 12 months) may be related to the slightly greater physical working capacity temporarily present in that group. The increase in the occupational adjustment score of the exercise training group was none the less small and should be seen in the context of multiple end points.

Our findings therefore do not support the claim that three classes a week of high intensity exercise are needed to improve aerobic capacity and psychosocial functioning after acute myocardial infarction. Given the wide eligibility criteria, large sample size, low drop out rate, and comprehensive range of outcome criteria of our study, these results should apply widely.

State anxiety scores in both groups are comparable with those of other patients who have been enrolled in group exercise programmes after having had an infarction. ${ }^{9}$ The low depression scores recorded for patients in our study are similar to those reported by others, who also found that most patients with heart disease have scores within the normal range on standard depression inventories. ${ }^{80}$ Depression usually has a subtle presentation and is often masked by denial. ${ }^{31}$ Therefore any impact of a rehabilitation programme on depression may be difficult to show. In any event, depression scores did not vary between the two groups of patients in our study.

To avoid observer bias psychological outcomes were measured by standard self report inventories rather than clinical assessment. These inventories were completed before follow up interviews because repeated interviews and physical assessments, including treadmill testing, ${ }^{32}$ could influence patients' perceptions of wellbeing.

The early enrolment of patients in a group exercise programme probably contributed to the high rate of return to work achieved by both groups in our study. As other studies have shown, early participation in a rehabilitation programme seems to be essential for a

\section{Clinical implications}

- High intensity exercise programmes facilitate physical and psychological recovery after acute myocardial infarction

- These benefits may accrue from participation in supervised group activity rather than from the intensity of exercise

- This study shows that high intensity exercise produces a higher level of fitness and a greater improvement in occupational adjustment than light exercise but such benefits are only temporary

- Similar long term effects on quality of life can be achieved by light exercise

- Light exercise programmes (which are less costly than exercise training) are recommended after acute myocardial infarction high rate of returning to work after acute myocardial infarction. ${ }^{33}$ We emphasise, however, that patients with multiple disabilities, cardiogenic shock, and poor English were excluded from our study.

Group light exercise and high intensity exercise training produce similar benefits after acute myocardial infarction. This finding has implications for the development of future low cost cardiac rehabilitation programmes.

This study was undertaken at the Austin Hospital, Melbourne, with the support of the National Heart Foundation of Australia.

1 Stern MJ, Pascale N, McLoone JB. Psychosocial adaptation following an acute myocardial infarction. Fournal of Chronic Diseases 1976;29:513-26.

Mayou RA, Foster A, Williamson B. Psychosocial adjustment of patients one year after myocardial infarction. $\mathcal{F}$ Psychosom Res 1978;22:447-53.

3 Wiklund I, Sanne H, Vedin A, Wilhelmsson C. Psychosocial outcome one year after a first myocardial infarction. 9 Psychosom Res 1984;28:309-21.

4 Bruce RA. The benefits of physical training for patients with coronary heart disease. In: Ingelfinger FJ, Ebert RV, Finland M, Relman AS, eds.
Controversy in internal medicine II. Philadelphia: W B Saunders, 1974.

5 DeBusk RF, Houston N, Haskell W, Fry G, Parker M. Exercise training soon after myocardial infarction. Am $\mathcal{f}$ Cardiol 1979;44:1223-9.

6 American Heart Association Subcommittee on Rehabilitation. Standards for cardiovascular exercise treatment programs. Circulation 1979;59: 1084-900A.

7 Clausen JP, Larsen OA, Trap-Jensen J. Physical training in the management of coronary artery disease. Circulation 1969;40:143-54.

8 Stern MJ, Gorman PA, Kaslow L. The group counselling versus exercise therapy study: a controlled intervention with subjects following myocardial infarction. Arch Intern Med 1983;143:1719-25.

9 Taylor CB, Miller NH, Ahn DK, Haskell W, DeBusk RF. The effects of exercise training programmes on psychosocial improvement in uncomplicated postmyocardial infarction patients. $\mathcal{F}$ Psychosom Res 1986;30:581-7.

10 Goble AJ, Hare DL, Macdonald PS, Oliver RG, Reid MA, Worcester MC. Effect of early programmes of high and low intensity exercise on physical
performance after transmural acute myocardial infarction. Br Heart $\mathcal{F}$ 1991;65:126-31.

11 Expert Committee on Cardiovascular Diseases and Hypertension. First report. Hypertension and coronary heart diseases: classification criteria for epidemiological studies. WHO Tech Rep Ser 1959;168:25-6.

12 Norris RM, Brandt PWT, Caughey DE, Lee AJ. Scott PJ. A new coronary prognostic index. Lancet 1969;i:274-81.

13 Norris RM, Caughey DE, Deeming LW, Mercer CJ, Scott PJ. Coronary prognostic index for predicting survival after recovery from acute myocardial infarction. Lancet 1970;ii:485-8.

14 Prineas RJ, Crow RS, Blackburn H. The Minnesota code manual of electrocardiographic findings. Boston: John Wright-PSG, 1982.

15 Wolk MJ, Scheidt S, Killip T. Heart failure complicating acute myocardial infarction. Circulation 1972;45:1125-38.

16 Peto R, Pike MC, Armitage P, Breslow NE, Cox DR, Howard SV, et al. Design and analysis of randomised clinical trials requiring prolonged observation of each patient. I. Introduction and design. Br 8 Cancer observation of each

17 Balke B, Ware RW. An experimental study of "physical fitness" of Air Force personnel. US Armed Forces Medical fournal 1959;10:675-88.

18 Bruce RA, Kusumi F, Hosmer D. Maximal oxygen intake and nomographic assessment of functional aerobic impairment in cardiovascular disease. $\mathrm{Am}$ Heart f 1973;85:546-62.

19 Spielberger CD, Gorsuch RL, Lushene RE. Manual for the state-trait anxiety inventory. Palo Alto: Consulting Psychologists Press, 1970.

20 Krug SE, Laughlin JE. Handbook for the IPAT depression scale. Champaign, Illinois: Institute for Personality and Ability Testing, 1976.

21 Jenkins CD, Stanton B-A, Savageau JA, Denlinger P, Klein MD. Coronary artery bypass surgery: physical, psychological, social and economic outcomes six months later. $\mathscr{f} A M A$ 1983;250:782-8.

22 Hackett TP, Cassem NH. Development of a quantitative rating scale to assess denial. 7 Psychosom Res 1974;18:93-100.

23 Eysenck HJ, Eysenck SBG. Manual of the Eysenck personality inventory. Bedford: Sidney Press, 1964.

24 Folstein MF, Luria R. Reliability, validity and clinical application of the visual analogue mood scale. Psychol Med 1973;3:479-86.

25 Gurland BJ, Yorkston NJ, Stone AR, Frank JD, Fleiss JL. The structured and scaled interview to assess maladjustment. I. Description, rationale and development. II. Factor analysis, reliability and validity. Arch Gen Psychiatry 1972;27:259-67.

26 Weissman MM. The assessment of social adjustment: a review of techniques. Arch Gen Psychiatry 1975;32:357-65.

27 Broom L, Duncan-Jones P, Jones FL, McDonnell P. Investigating social mobility. Canberra: Australian National University, 1977.

28 SPSS. SPSS- $X$ user's guide. 3rd ed. Chicago: SPSS, 1988.

29 Blumenthal JA, Rejeski WJ, Riddle MW, Emery CF, Miller H, Roark S, et al. Comparison of high and low intensity exercise training early after acute myocardial infarction. Am $\mathcal{F}$ Cardiol 1988;61:26-30.

30 Blumenthal JA, Emory CF, Rejeski WJ. The effects of exercise training on psychosocial functioning after myocardial infarction. Fournal of Cardiopsychosocial functioning after myocardian

31 Dimsdale JE, Hackett TP. Effect of denial on cardiac health and psychological assessment. Am F Psychiatry 1982;139:1477-80.

32 Ewart CK, Taylor CB, Reese LB, DeBusk RF. The effects of early postmyocardial infarction exercise testing on self-perception and subsequent physical activity. Am $\mathcal{f}$ Cardiol 1983;51:1077-80.

33 Saeterhaug A, Nygaard P. Early discharge and early rehabilitation and return to work after acute myocardial infarction. foumal of Cardiopulmonary Rehabilitation 1989;7:268-72. 